$\ddot{0}$ STFM SOCIETY OF TEACHERS OF From the Society of Teachers FAMILY MEDICINE of Family Medicine

Ann Fam Med 2013;580-581. doi:10.1370/afm.1597.

\section{STFM FUNDS DEVELOPMENT OF A RESIDENCY ACCREDITATION TOOLKIT}

In July 2014, family medicine residency programs will be asked to implement the Next Accreditation System. Programs will need to start reporting data to ACGME in December 2014. This new outcomes-based accreditation process will be a drastic change for programs, and compliance affects program accreditation.

At a recent Board of Directors meeting, STFM approved the development of resources to help members in residency programs implement process changes to meet new accreditation requirements and establish faculty development on the new requirements. Ted Epperly, MD, president and chief executive officer of the Family Medicine Residency of Idaho, Boise (FMRI) will serve as chair of the newly formed Residency Accreditation Toolkit Task Force. Dr Epperly reports, "The Residency Accreditation Task Force is underway and busily determining the simplest, most efficient and highest value way to help all residency programs prepare for the New Accreditation System. What we will create is a one stop shop that will be smorgasbord of helpful tools, templates, best practices and resources for family medicine residency programs and departments to use. Keep your eyes tuned for the work of this group that will be rolled out in July 2014."

Dr Epperly is currently a member of the ACGME Board of Directors and served on the ACGME Residency Review Committee from 2004 to 2008. He also serves as one of the co-chairs on the Patient Centered Primary Care Collaborative (PCPCC) Center on Care Delivery and Integration. He is a past board chair and past president of the American Academy of Family Physicians. He retired as a colonel from the US Army in 2001 and returned to his home state of Idaho to serve as program director at FMRI from 2001 to 2013.

Task force members were selected through an open call to the STFM membership, direct invitation to individuals with specific expertise, as well as an invite to other residency-focused organizations to submit candidates. Members of the task force are: Ted Epperly, $\mathrm{MD}_{i}$ Brandy Deffenbacher, MDi Timothy Graham, $\mathrm{MD}_{i}$ Beth Anne Fox, MD, Jeff Haney, MDi Barbara Joyce, $\mathrm{PhD}_{i}$ Tina Kenyon, $\mathrm{ACSW}_{i}$ Richard Neill, $\mathrm{MD}_{i}$ Judith Pauwels, MD; Erika Ringdahl, MD; and Fred
Miser, MD, AFMRD Liaison Stan Kozakowski, MD, Residency Program Solutions Liaison.

The task force will develop several resources, many of which are outlined below. This list of resources will be refined by the task force, taking into account feedback from the fall 2013 member needs assessment.

1. An online Accreditation Toolkit. The toolkit will contain concise, how-to information on addressing the key components of the Next Accreditation System. It will include the following sections and components: a. Milestones

i. An updated Resident Competency Assessment toolkit that is more closely aligned with the Milestones. The update will include the addition of links to existing tools for: faculty member assessments of residents on rotations, self-evaluations, peer evaluations, and evaluations by nurses and other staff members.

ii. Online evaluation/tracking forms and potentially a mobile app for storing and displaying formative and summative evaluations and individual and program progress by milestone

iii. An online module on how to incorporate formative feedback into daily practice

iv. Guidance on how many assessments are needed for any given milestone

v. Vignettes from family medicine residency programs that participated in Milestones pilots

vi. Tips on interventions for residents who are not progressing in alignment with their peers in one or more areas

b. Clinical Competency Committee

i. How-to information on composition and procedures of the committee with an emphasis on conducting efficient semi-annual reviews

ii. Clinical Learning Environment Review (CLER) visits

iii. An overview of what these visits are and how to prepare

iv. Resources, tools, links, tracking forms, and faculty development on the six areas that will be assessed during CLER visits (for example, resources could include curriculum on professionalism, clinical quality improvement, and patient safety and a faculty development module on fatigue management)

v. Tips on/examples of a quality and safety strategy and policies on supervision, duty hours, and related matters

c. Faculty Survey i. Sample survey

d. Scholarly Activity

i. Definition

ii. Links to opportunities 
iii. Sample tracking form

e. Self-Study Visits (resources to be developed at a later phase of this project)

2. STFM will explore the development of a mobile app to track patient encounters/procedures

3. STFM will address faculty development needs through STFM conferences and On the Road presentations

Plans are to launch the accreditation toolkit, with the exception of online modules, online forms, and mobile applications by July 30, 2014. Faculty development modules and training will follow.

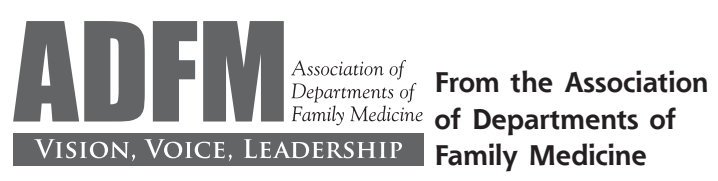

Ann Fam Med 2013;581-582. doi:10.1370/afm.1588.

\section{ANOTHER CENTURY OF "REFORM WITHOUT CHANGE?"}

"And the seasons, they go round and round And the painted ponies go up and down We're captive on a carousel of time"

(Joni Mitchell 1970)

The 1910 Flexner report is credited with beginning the modern era of medical education. ${ }^{.}$Since that time, a regular calliope of calls for changes in the way that medical students are selected and educated has been heard. Yet authors such as Bloom ${ }^{2,3}$ and Christakis ${ }^{4}$ have noted that these calls for reform are 'remarkably consistent,' with perennial themes and similar recommendations. Whitehead ${ }^{5}$ likens this revolving pattern to a carousel, observing that "medical educators were regularly returning with fresh and un-remembering minds, to the same concerns."

What are the reasons that the same "ponies go up and down $n_{i}$ and is the current wave of curricular reforms likely to yield any different results? Will proposed reforms overcome the resistance to fundamental change that has so far stymied the reformers' stated desires to achieve a system of medical education to better serve the needs of the public? One source of resistance to real change was pointedly cited by Bloom: "The scientific mission of academic medicine has crowded out its social responsibility to train for society's most basic health-care delivery needs."

Comprehensive reviews of curricular reform by Christakis $^{4}$ and Whitehead ${ }^{5}$ found similar conclu- sions, emphasizing the need for increased generalist training and concerns about overspecialization. In the 1990s, curricular reform efforts funded by the Health Resources Services Administration and private foundations enthusiastically initiated novel curricular changes. Academic institutions watched a transient increase in medical student selection of generalist disciplines. The failure of a concurrent systemic reimbursement reform contributed to another decline in student interest in primary care. ${ }^{6}$

New reports promote novel efforts to reshape the health care workforce for the 21st century. ${ }^{7,8}$ Coupled with a parallel wave of curricular revision, what factors offer hope that academic institutions will go beyond focus on the oft-recommended goals of selecting the right medical students, providing a more suitable curriculum through more suitable methods, and encouraging a professional identity that is immune to the hidden curriculum? This hidden curriculum, including what Funkenstein" called "the ideology of the era," has obstructed the most idealistic of curriculum planners' intent to influence students' perception of generalism and the relevance of population needs to their particular specialty choice.

What is required to hold academic medical centers accountable for preparing a workforce capable of improving population health? How much of the hidden curriculum and influential "ideology of the era" can academic medical centers control?

Surveys suggest that most $(53 \%$ in 2011 and $65 \%$ in 2012) chairs of academic departments of family medicine are being asked to lead health care delivery innovations. Family medicine educators across the country are emphasizing patient-focused team-based learning, incorporating cost/value issues and practicebased quality improvement projects into medical student experiences. Departments of family medicine are leading unique public health initiatives and demonstrating the value of primary care physicians' role in improving the health of the public. Is this enough? Or will academic institutions continue to "impute novelty" to curricular issues and continue to avoid examining factors linking resistance to change with the continued struggle to prepare a health care workforce best suited to address the health needs of our citizens?

The opinions are those of the authors. They do not represent official policy of the Department of Defense, the Department of the Navy or the Uniformed Services University.

Christine Matson, Ardis Davis, Mark Stephens, and the ADFM Education Transformation Committee

\section{References}

1. Flexner, A. Medical Education in the United States and Canada. New York, NY.: Carnegie Foundation; 1910. 